\title{
The Concept of Sustainability in Contemporary Architecture and Its Significant Relationship with Vernacular Architecture of Iran
}

\author{
Leila Damirchi Loo ${ }^{1} \&$ Mohammadjavad Mahdavinejad ${ }^{2}$ \\ ${ }^{1}$ Department of Architecture, Karaj Branch, Islamic Azad University, Karaj, Iran \\ ${ }^{2}$ Department of Architecture, Tarbiat Modares University, Tehran, Iran \\ Correspondence: Mohammadjavad Mahdavinejad, Department of Architecture, Tarbiat Modares University, \\ Tehran, Iran.
}

Received: October 22, $2016 \quad$ Accepted: November 17, $2016 \quad$ Online Published: February 3, 2017
doi:10.5539/jsd.v10n1p132
URL: http://dx.doi.org/10.5539/jsd.v10n1p132

\begin{abstract}
The energy crisis in 1970s and environmental problems following that affected many human activities and caused the field of architectural design, as one of the factors contributing to the high consumption of energy, to face a difficult challenge. Hence, the issue of environmental protection, the need for future generations and enjoying free energies, proposed a new concept as "sustainability" in all sciences. According to the studies conducted, the principles of sustainable architecture have been partially met in many of our local and traditional buildings. The main aim of this study is to investigate the concept of sustainability and describe its relations with the vernacular architecture of Iran. In this regard, this study is supposed to give an appropriate response to the problems raised using library research and analytical-descriptive method; and finally by investigating and analysis of various specifications sustainable architecture, to provide design principles of sustainable architecture in the current era.
\end{abstract}

Keywords: sustainability, sustainable development, sustainable architecture, vernacular architecture

\section{Introduction}

As a result of disrupting the balance of life, getting away from nature and human values, lack of attention to environmental and vernacular factors, dominative behavior and instrumental use of nature, modern human is encountering crisis and a vague hazardous future. This has caused gradual formation of an approach called sustainable development. Sustainable development includes providing solutions against traditional, physical, cultural, environmental, and economic patterns of development, which can prevent problems such as destruction of natural resources, destruction of ecosystems, promoting injustice, pollution, uncontrolled population increase and the low quality of human life. Thus, specialists in the field of building effort for the development and deployment of construction materials and methods of design, production, and implementation based on environmental protection in terms of sustainable development and sustainable architecture. In discussing sustainable development and consequently sustainable architecture, the issue that each building should interact with its context and surrounding natural environment has become something evident. The controversial and the most considered part in this topic is how to interact and type of measures intended. Accordingly, in this research, in addition to providing definition of sustainability, sustainable development, it is tried to state indicators for sustainability development in architecture design by investigating principles of sustainability in architecture and according to the guidelines provided in vernacular architecture of Iran. Accordingly, in the following, definitions of sustainability, sustainable development, sustainable architecture and design principles in this view of architecture, will be discussed by analytical - descriptive method. 


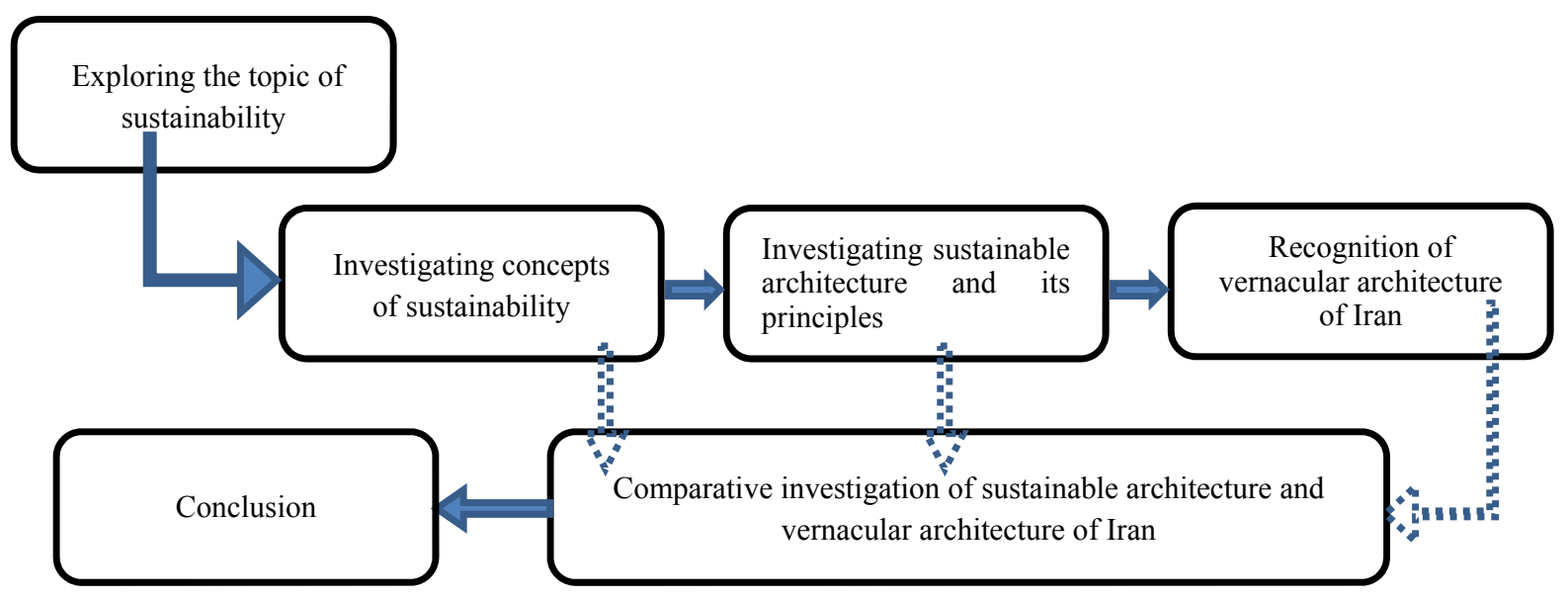

Figure 1. Process of research and analysis by author

\section{Research Background}

Unconscious sustainable development is related to before the industrial and technological revolution in Europe when human beings, due to lack of access to machines science and technology and the use of natural forces like wind, water and livestock, power of hands and simple industry could not make significant contamination or excessive exploitation. Unstable development is related to new centuries that due to human access to advanced machines, fossil fuels, increase of population, and consequently excessive increase of demand and context for unsustainability of nature areas and biological crisis, has brought social and cultural transformations and decrease of the power of religion and prevalence of environmental selfishness. Informed sustainable development has been forming in recent decades; by interest and tendency of the public, especially people in the developed world towards environmental issues, and some politicians and the rich and influential peoples' getting aware to comply with environmental issues in industry and exploitations, developing countries' becoming aware of the dangers of environmental crises and advances in, eco-friendly technologies and the emergence of green thinking, green industry, green service, green agriculture, and green culture in modern societies, informed sustainable development gets more and more accepted among communities.

Sustainability is a word that includes many complex aspects. Today, the word sustainability is considered and used a lot in society. Sustainability, due to its fundamental slogans which are inclusive and target preservation of land, makes recommendation for achieving realistic and workable solutions on the one hand and support for diversity in the nature, on the other hand. Since there is no definite method or recommendation sustainable architecture, attention to the discussions and opinions expressed in this field is essential to inform architects.

\section{The Concept of Sustainability}

The concept of sustainability in the 1970s can be considered as logical result of a new awareness of global environmental issues which in turn was influenced by factors like environmental movement of the 60s, publication of books such as restrictions of growth, and the first United Nations Conference on Environment and Development held in 1972 in Stockholm. Lexical meaning and the present meaning of the word sustainability in this discussion is what "can continue in the future". Dehkhoda has brought sustainability as durable and lasting.

Table 1. Meaning of the word sustainability in dictionaries

\begin{tabular}{lllll}
\hline References & Definition & Definition reference & vRaw \\
\hline 1 & Dehkhoda dictionary & & Sustainability is referred to as lasting and durable & Dehkhoda \\
\hline & Meaning and root of & Sustain: protection, keeping alive, permanent continue & \\
& sustainability in $\quad$ Latin & Sustainable: lasting, an attribute that describes something & Azerbaijani,Mofidi,138 \\
2 & dictionary & & causing peace, nutrition and provision of life and so leads & 2,351 \\
& & to life lasting and making it long & \\
& & &
\end{tabular}


The word stable meaning fixed, remaining, permanent,

long lasting, durable against transient.

The word sustainable is used today extensively for

describing the world in which human and natural systems

View of some specialists

can continue together.

Mofidi et al., 1386,47

Bahreini et al 2001,47

Sustainability as a Present participle is situation in which

Zahedi et al ,2005,57

desirability of facilities along time is not decreased and

indicates long term protection or duration

\subsection{Sustainable Development}

According to the definition of Brundtland Commission, sustainable development is kind of development that meets the current needs without compromising and regardless of abilities of future generations. Sustainable development is a comprehensive approach to improve the life quality of people in order to achieve economic, environmental, social prosperity of human settlements. Perhaps we can also rely on simple definition and process-oriented: "Sustainable development is development that considers human health and ecological systems in the long term ability of future generations to get their needs." In line with the objectives of sustainable development, relationship between architecture is of great importance and environmental issues that threaten humanity's future, have made architects to look for solution.

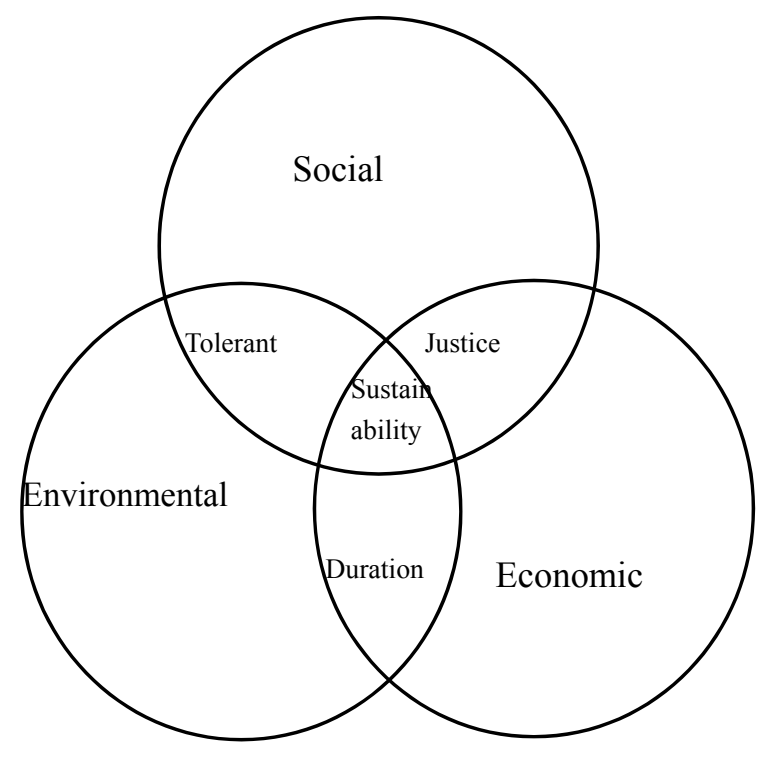

Figure 2. Graph of sustainable development indicators

\subsection{Paradigm of Sustainability}

Much of the attention in the history of the main development paradigm has been devoted to paradigm of growth and its pattern has been industrial pattern. Industrial pattern caused particular attention to the industry and encouragment of urban development and includes the thinking that economic growth, through leaking wealth down will improve economic conditions of poor households. Industrializing also means use of industrial pattern that is associated with the concepts of division of labor, opportunity, and cost, comparative advantage and economies of scale. The fundamental properties of industrial pattern that is characteristic of modernity, are as follows: A- simplification (division of labor in certain components), B -normalization and C- machining.

Peter Draker beleves that we are in the midst of a great transformation from an industrial society to a post-industrial society. Drucker in his book "new realities", says the biggest change in society is knowledge in which manual labor changes to knowledge labor and this is logical conclusion of long-term transformation of manual labor to industrial labor (work by machine) and finally to knowledge labor. There are not much documentation about the emergence of a new paradigm or sustanability paradigm. Paradigm that fits the needs of 
postindustrial or postmodern human and its pattern is also sustanbility pattern.

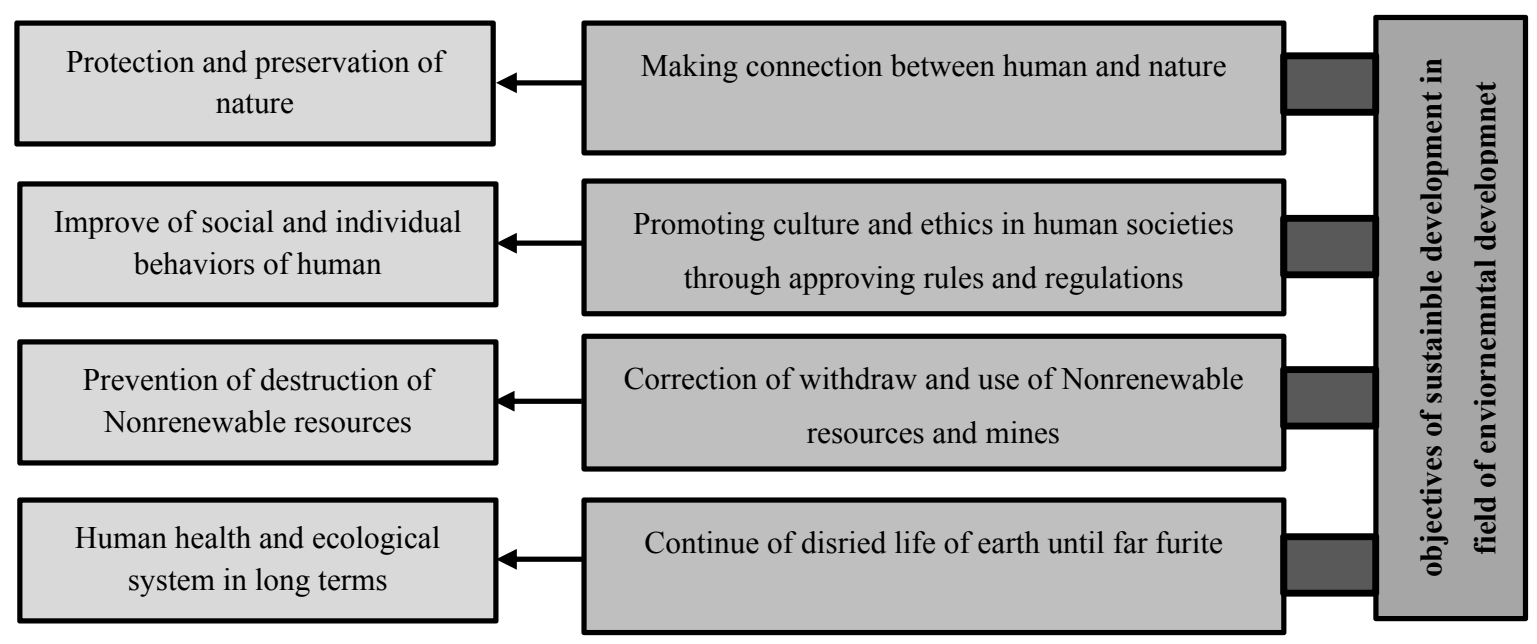

Figure 3. Objectives of sustainble development in field of enviornemntal developmnet (author)

\section{Concept of Sustainability in Architecture}

The word sustainability has been used with its current meaning which is "what could be continued in the future". Concept of sustainability in architecture is not that we create structures that will simply last long because structures with several hundred years are not consistent with the needs of the present time. Architecture can be called sustainable that are responsive to the needs of their present. In new issues of sustainable architecture it is attempted to reduce the negative impacts of new architecture on the environment and instead of that energy is saved through the use of materials consistent with the environment, especially climate. Sustainable buildings are considered buildings that have "least damaging effects on artificial and natural environment, the area immediately adjacent and around them as well as their overall context. Sustainable buildings have attention to all the lifecycle of building, environment with high quality, good performance and the future ".

Table2. Three major criterai of sustainbility concept

\begin{tabular}{|c|c|c|c|c|}
\hline $\begin{array}{l}\text { criterai of } \\
\text { sustainbility } \\
\text { concept }\end{array}$ & The fields considred & $\begin{array}{l}\text { Dominant } \\
\text { field }\end{array}$ & Symbolism / aesthetic & Approach \\
\hline Natural & $\begin{array}{l}\text { Environmental place, } \\
\text { echology,sanitaion, } \\
\text { balance }\end{array}$ & local & $\begin{array}{l}\text { Use of natural forms reflecting } \\
\text { natural features }\end{array}$ & $\begin{array}{l}\text { Study of local natural systems, } \\
\text { emphasis on sensory and human } \\
\text { features of nature }\end{array}$ \\
\hline Cultural & $\begin{array}{l}\text { Cultural Place,human, soul, } \\
\text { differences, Cultural sustainbility }\end{array}$ & local & $\begin{array}{l}\text { Local forms related to } \\
\text { enviorment, use of local } \\
\text { material and building } \\
\text { techniques }\end{array}$ & $\begin{array}{l}\text { Study of local culture and } \\
\text { buildings, focus on participation } \\
\text { of local people and experts }\end{array}$ \\
\hline Technology & $\begin{array}{l}\text { Technologies,major climatic } \\
\text { impacts, cost-profit analysis,crisis } \\
\text { managment }\end{array}$ & world & $\begin{array}{l}\text { Lomited use of international } \\
\text { systaems }\end{array}$ & $\begin{array}{l}\text { Study of econmic and technoligy } \\
\text { sciences, focus on internaltional } \\
\text { speciltyies }\end{array}$ \\
\hline
\end{tabular}

\subsection{Sustainable Development and Architecture}

Understanding the environment and architecture is possoble just by recognizing human activities in the world around them, and target of architecture can be considered as creating human ideas within a physical form. Human design is the most important principle of sustainable design that deals with viability of all components of 
the Global Environment. This principle is deeply rooted in the need to maintain the chain of biological systems, the survival of human survival depends on them. The most essential role of architecture is creation and production environments that maintain mental health, wellbeing, safety, physical comfort and productivity of its inhabitants. The application of sustainability concepts in architecture has opened a new discussion called "sustainable architecture", "ecological architecture", "green architecture" or "ecological architecture", all of which have the same meaning and indicate concept of eco- friend architecture.

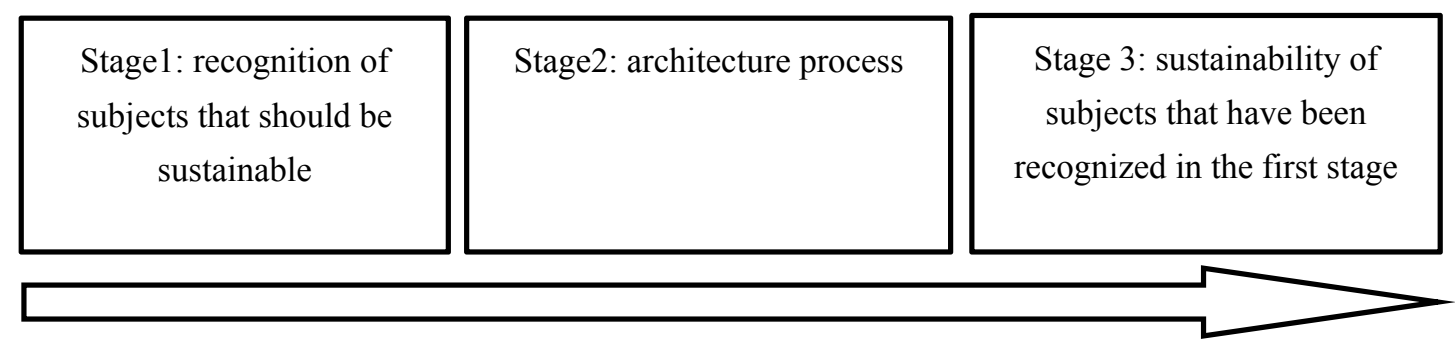

Figure 4. Three stages of the process of sustainable architecture

\subsection{Background of Sustainable Architecture}

The main root causes of environmental protection and sustainable architecture movements go back to the 19th century. John Ruskin and William Morris and Richard Latab, are pioneers of sustainable architecture. Ruskin says in his book "The Seven Lamps of Architecture" that harmonic order found in nature can be modeled to achieve growth and progress. Morris suggested returning to green space of suburbs and self-sufficiency and revitalization of local industries. Latabi in one of his treatises asked architects appreciate order and beauty of nature. All these pioneers have used the term nature and the only word that could well be replaced by this term is "sustainable architecture". Years later, other architects such as Frank Lloyd Wright, Peter Eisenman and others continued and expanded ideas of these pioneers. The buildings designed according to sustainable architecture were partly fluid and flexible, as opposed to fixed and old buildings. So that, according to Richard Rogers strengths and weaknesses of a building will have a direct impact on the ecosystems of the world.

\subsection{Sustainable Design}

In proposed definitions for sustainable design sometimes the idea of environmental sustainability in relation to architecture is emphasized more. For example the following definition: "sustainable building is the building that has the least adverse effect on the natural environment in the lifetime of building and regional and global establishment." The term sustainability was defined for the first time by the World Commission on Environment and Development in the United Nations as follows: "Sustainability is meeting the needs of the present generation without distorting the ability of future generations to meet their own needs." Sustainability in the areas of urban life was introduced in the three branches of social, economic sustainability and environmental sustainability and to achieve environmental sustainability, architects in the past two decades were looking to develop methods and principles that are known as sustainable design, sustainability in architecture and green architecture. Today, global warming and the ozone layer's being in danger, has been accepted as a fact. Much of the atmosphere pollution, which in some cases is due to the earth warming, is caused through burning of fossil fuels in energy production process for urban living.

Much of the pollutants that cause environmental damages can be directly attributed to the process of building. For example, 50 percent of the world's fossil fuel consumption is directly related to services and use of buildings; these two cases alone produce $50 \%$ of carbon dioxide in the world, which includes over a quarter of greenhouse gases. On the other hand, growth of urbanization has led in turn to produce massive amounts of pollution, resource consumption, etc., and has resulted in rapid rise of urban poverty. Architects, owners and users of buildings, by correct choice of environmentally suitable materials, use of a process of ecological design and responsible attention to the use of buildings, minimize environmental consequences of urban growth. In order to get ideas for ecological and sustainable architecture, there is no need to travel far, and this type of architecture can be found in the vernacular architecture of the past. However, perhaps the solution of contemporary environmental problems cannot be found in this type of architecture and therefore new approaches to this end must be adopted. One of these approaches is suggested by Jang Jin Kim from the University of Michigan to provide the three laws of sustainability in architecture: economic resources, design of life cycle and human design. He defined three laws as follows: "Economic resources associated with the reduction, reuse and 
recycling natural resources entrance to a building. The design of life cycle is a kind of methodology to analyze the process of building and has impact on the environment. Human design also focuses on the interaction between humans and the natural world ". It is obvious that with the economic recovery, demand for architectural resources (land, buildings, building materials, energy, etc.) will increase. This will in turn increase impact of architecture on the global ecosystem that consists of inorganic elements, living organisms and organic material. The aim of sustainable design is architectural solutions, which can guarantee prosperity and coexistence of these three groups. To achieve this goal, there is no escape except the formulation of rules and regulations that designers, implementers and beneficiaries by respecting them not only reach the goal of defining sustainability that was referred to in the beginning, rather green architecture literally, makes view of cities and buildings more people like. In fact explaining the principles will help everyone, rather than standing up and resisting against nature, not only to accompany it, but also to enjoy its gifts and strengths to the benefit of our architecture. Principally, sustainable design is as a three-way interaction between architecture, user and nature.

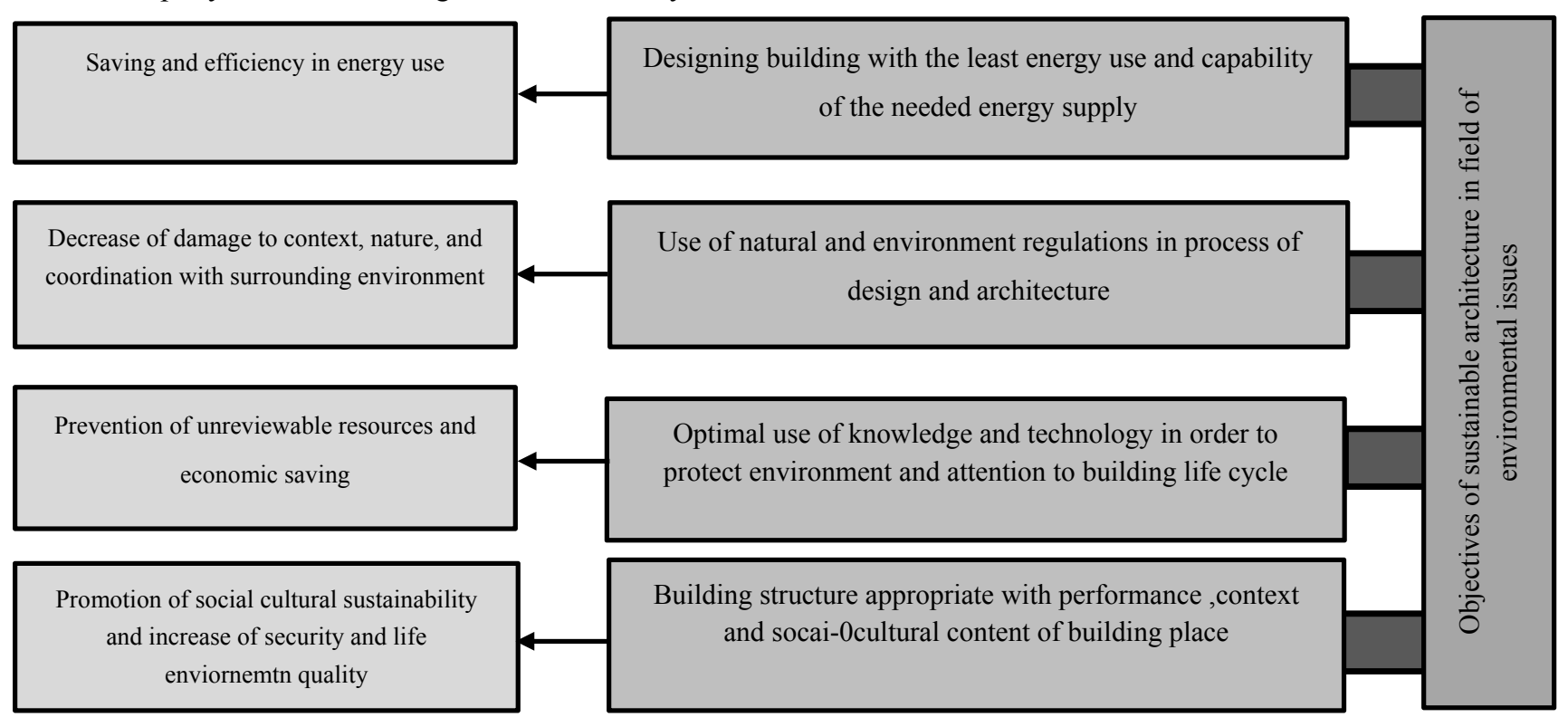

Figure 5. Objectives of Sustainable Architecture in environmental field [author]

\subsection{Principles of Sustainable Architecture}

1) Influence of cultural, environmental and climatic conditions

2) Harmony and consistency with nature and the environment,

3) Energy Saving,

4) Correct response to operational needs,

5) Influence of vernacular architecture but as modern, and

6) Correct use of material both visually and environmentally.

\subsubsection{Principles of Sustainable Architecture (Green Building)}

How to design our homes and select materials is one of the most important issues that affect the future of our buildings. In general, green architecture is based on four principles: (a) protection of energies of water, wind and other natural resources, (b) provision of environmental health, (c) growth of economy in country, (d) provision of high quality of life for citizens. These principles are subcategories structural effective factors in sustainable architecture: (a) geography, (b) culture, (c) vernacular architecture

In general, green process argued that all issues are related to each other and in every decision making all of its aspects must be examined and thus, the idea of investigating principles separately is in contradiction to it. Many solutions have been proposed on sustainable architecture. 
Table 3. Comparison of Sustainable design principles from overall vision and Hart - Brenda Will [Author]

\begin{tabular}{ll}
\hline \multicolumn{1}{l}{ Principles of sustainable architecture } & \\
\hline $\begin{array}{l}\text { Principles of sustainable architecture from general point of view } \\
\text { and RenaHart }\end{array}$ & $\begin{array}{l}\text { Principles of sustainable architecture from point of view of Brenda, } \\
\text { and Robert Will }\end{array}$ \\
\hline Thinking limitedly & $\begin{array}{l}\text { Protection of energy } \\
\text { Work with climate }\end{array}$ \\
Heating building by sun & Decrease of using new resources \\
Keeping comfort and welfare & Respect to users \\
Using renewable energies & Respect to site \\
Storing water & \\
\hline Using local material & \\
Protecting natural forests & Holism \\
Using recyclable material & \\
Using durable material & \\
Production of consuming food & \\
Maintaining produced food &
\end{tabular}

\section{Vernacular Architecture from the Perspective of Nature and Its Meaning}

Today, when speaking of vernacular architecture, we face a set in which there are forms from past; much of vernacular architecture, in any land that is discussed, is considered as a legacy of the past and the mentality that they can also create architecture today and has ability to accommodate all the features of the vernacular architecture of its past, is suggested less.

So here we're going to look from another angle to architecture and vernacular architecture and pay attention to the range of possibilities, obstacles, requirements, materials, origins and efforts that anyone who reaches production of the made space, inevitably is faced with. Bruce Allsopp in the book "a new theory in architecture" in the definition of vernacular architecture notes that vernacular architecture is popular design approach that is people born from public architecture and can be considered as the advanced form of natural architecture of a given territory which is expressed in relation to climate, culture and building materials. Vernacular architecture is compatible with the ego and the environment joints with people and compatible environment. This architecture, more than being worthy of praise, is worthy of love ". Perhaps the most pervasive and most comprehensive definition of vernacular architecture can be expressed as the architecture in which harmony with nature, respect for other people and their houses, so the respect for the entire environment, whether it is man-made or natural environments are seen. Formed in any medium, such architecture can coordinate and match with its demands in different ways. "Therefore, it is firmly determined that the relationship between ecology and the natural environment of human is the key in most vernacular architecture. Examples of traditional culture and vernacular architecture framework that can be found at the present time, each has hidden signs of dynamic evolution in different periods of history.

\subsection{Vernacular Architecture in Iran}

In studies conducted to understand the architecture and urbanism in Iran, it has always been attempted to split shape and structure of buildings and cities. It can be said, the old Iranians, about 50 years ago before arrival of unconditional culture of global architecture and urbanization to our country, have taken advantage of their natural environment and their gifts in the simplest form and have integrated their home with it. Vernacular architecture can mean recognition of society, the society that has continued to be in conflict with nature for survival from the beginning of the formation. Today, modern technological facilities and reflections of industrialized life had great impact in reshaping the production process of past architecture and brought two discrete periods from each other, so much that their connection seems to be very difficult. It must be understood that what happened in the past that determines the way of the future, on the other hand, enjoying and getting inspiration from models used in past life to extract forms from them as a escape from the realities of today's basic requirements, has sometimes risky results. The past, present and future should be combined with each other to create a continuous combination and architecture that follows its movement in the direction of giving value to the concept of life, with freedom of forms and harmony of form with purpose, has place in this fusion. In this 
respect, informed participation of people in building and forming their cities can be effective and have constructive help in keeping alive the roots and values, which is evident in the local architecture of the past.

\subsection{Equalizing Localization Concepts with the Concept of Green and Sustainable Buildings Titles}

Indeed the titles green and sustainable are attributes that specify presence of compatibility with the environment and sustainability in a subject or artificial like building. An environmentally friendly, sustainable and intelligent building can be exploited using the most advanced technology. A sustainable and green building not only is not against nature, but also is formed alongside and in parallel to it to exploit more the environmental resources and human welfare. These building are set and controlled using advanced and harmonious natural environmental conditions and systems. Architectural design of builder, In addition aesthetic and good performance of spaces, tries to maximize the use of natural resources such as renewable energy, solar energy, geothermal energy, and wind and plants energy. Modern building technologies have emerged for setting the environmental conditions and for comfort of operators to achieve a sustainable and compatible environment and to harmonize ecology and ecotech. Detailed architectural design, appropriate materials selection and use of advanced electronic systems are characteristic of such buildings that should be used in order to achieve the goals of sustainable architecture. On this basis, along with the latest technological developments in the design and construction of large structures in the world, buildings have used equipment such as air chimneys, mirrors reflecting the sunlight, smart skins, greenhouses, heat exchangers and other climatic elements to meet needs of residents of the building and use energy efficient in the best buildings of the future and are dynamically linked with the surrounding climate. For this purpose, sunshine degree, wind speed and direction and other climatic factors in different seasons are perfectly measured and modeled on the layout of the building. In sustainable buildings, using innovative technologies, materials are selected in such a way that there is lower power consumption and more savings in fossil fuels in cycle of production and operation. And also after ruin, they cause the least harm to the environment. One green and sustainable building can also be a smart building that through utilizing different advanced systems such as adjusting heating and cooling, lighting, security and safety systems, etc., in addition to saving in conventional energies (fossil fuels) and taking advantage of new energies, provide physical, emotional and psychological comfort of beneficiaries to great extent. The outer shell of building can be designed and act intelligently similar to human skin using the most advanced technologies. As human skin reacts against cold, heat, moisture and air, the building shell also using special sensors in double glass, shutters and thermal animated insulation, is sensitive against amount of sunshine, shadow, current of weather, and other environmental conditions and heat loss hot during the day in the warm and cold seasons of year and reacts and controlled by a computer system.

Table 4. Features of vernacular architecture of Iran and sustainable architecture

Point of view

Traditional

architecture of

Iran
Nasr, 1374,49

Ardalan,1374,16

Pirnia,1382,26

Abolghasemi,2005,76

Diba, 1378,97.105

Pourjafar, 1388

Sustainable 1-symbolic view 2-enviornemtnal consistency3-heaven sample4-positice space systems5-innovation

Sattari sarbnagoli 1388

architecture

1-people-orientation2-avoiding uselesness3-maintenace4Autarchy5-

Introspection

Creation and design and implementation of building, prefer divine feeling to beauty feeling

Creation of an spiritual environment for approaching God 
1- Introspection 2-centrality3-reflection4- connection of architecture with

natur5- geometry6-transparency and continuity 7-secret and vague

8-balnace/ sensitive balance

Attention to values, beliefs, and norms of society( religious and cultural)

Influence from cultural, environmental and climatic conditions

Coordination and consistency with environment and nature

Saving in energy consumption

Correct response to performance needs

Influence from vernacular architecture but as modern

Correct use of material both visually and environmentally

\begin{tabular}{lll}
\hline Common & Integrity and consistency with environment & Shafiian et la 2014 \\
points & Prevention of pollution & \\
& Using natural energies( renewable) \\
\hline
\end{tabular}

\section{Conclusion}

In recent decades, the topic of sustainability for protection of environment and the need of future generations has been common in Applied Sciences. Architecture science and consequently building is among sciences, which can be risky for the environment and nature and at the same time has the capability to bring them into service of building by proper design and according to identification of beneficial climate of each area. Among vernacular architecture of Iran with history of several thousand years, recognition of climate and culture of each ethnic group has been formed. Sustainable architecture approach also requires appropriate local infrastructure. Traditional methods that have led to creating a shelters that have been sustainable over the centuries, today cannot afford needs and resources of the present time. Thus, here vernacular architecture means paying attention to its values. Attention vernacular features, is significant for two reasons: one is creating a favorable environment for the development of sustainable architecture and the other is use of replicable values of vernacular architecture in the architecture process. Although the principles of sustainable architecture includes a wide range of application of the simplest methods to the most sophisticated technologies of day, but the question is appropriateness of method and its compliance with the social and cultural environment and its users. Given the extent of the problem of sustainability and complex and interrelated aspects this issue, it is necessary to pay attention to one thing, and that is to consider sustainability as a product of architecture process. Sustainable architecture needs to be seen in relation to the process. A power that makes sustainability can be sustainable because in this case the basic question arises, that what must be sustainable and here is where solutions can be recognized. Application of the principles of sustainable architecture and its integration with environmental issues may prevent pollution and environmental degradation as well as energy saving in addition to create a comfortable space for life.

What was said about sustainable architecture represents a view of architecture that refers to several fundamental points: quality-orientation, paying attention to the future, environment and synergy of sustainability principles indices. For achieving sustainable architecture, it is also essential that a landscape is set by adopting an integrated approach, a coherent and homogeneous agenda with synergy of social and environmental aspects, so that brings growth and prosperity for all people in every place and time.

\section{References}

Ahmadi Torshizi, M. (2008). Urban and Rural Mangement Encyclopedia, Municipalities Organizations Publishing, Tehran. P. 294-295.

Ahmari, N., \& Forsat, M. (2014). biological approach to sustainable architecture. the Second International Congress of constructions, architecture and urban development, Tabriz.

Ahmedi, M., \& Pir Mohammad, M. (2015). the place of sustainable architecture in relation to vernacular architecture appropriate to the climate. National Conference on civil and architectural with sustainable development approach, Islamic Azad University, Fuman and Rasht branch, Fuman.

Aloopse, B. (1992). a new theory in architecture. translation by Parviz Forouzi, first edition, p. 52.

Armghan, M., \& Gorji Malhbany, Y. (2008). values of Iranian local architectural in relation to sustainable 
architecture approach. environment and rural housing, 20-35.

Aslani, R. (2001). sustainable development, definitions and perspectives. journal of housing and rural environment, (93), 43.

Azizi, M. (2001). sustainable urban development and analysis of the global views. Journal of the Safe, XI(33), 14.

Dadkhah, M. (2005). pass on vernacular scope (2nd ed.). Cultural Space Science Institute, Tehran, p. 71.

Falamaki, M. (2005). vernacular architecture (2nd ed.). Cultural Space Science Institute, Tehran, p. 35.

Hatami Golzari, E. (2008). Traditional Iranian Architecture and Sustainable Development. journal of infrastructure engineering, (6), 37.

Kamran Kasmaee, H., Barati Fard, A., \& Ghaffari, P. (2011). attitudes and principles of sustainable architecture. National Conference of Civil Engineering, Architecture, Urban Planning and Energy Management, Islamic Azad University, Ardestān.

Mori, K., \& Christodulou, A. (2011). Review Of Sustainability Incidences and Indicators: Towards A.

Munier, N. (2005). Introduction to Sustainability: Road to a Better Future. The Netherlands: Springer.

National Research Council. (1999). Our Common Journey: A Transition Toward Sustainability. The National Academies Press.

Nilforooshan, M. (2010). applications of new patterns of sustainable architecture in the use of natural light and effective solutions in energy efficiency and avoiding wasting electricity in schools. the second conference of reforming the electrical energy consumption pattern, Ahvaz.

Rostami, S., Turkish, \& Torki, O. (2014). An Inquiry into the effectiveness of model of sustainable construction patterns. the Second International Congress of constructions, urban architecture and development, Tabriz.

Samani, Gh., \& Pourjafar, M. R. (2012). Study of sustainable development indicators in the traditional market of Tabriz. Journal of Geography and environmental studies, (2), 51-54.

Satari Sarbangholi, H., \& Nadri, N. (2012). comparison of indicators of sustainable architecture in the contemporary era with the teachings of the Holy Quran. journal of literature and religious art, (4), 73-103.

Shafieian Dariani, F., Pourjafar, M. R., \& Ghobadi, A. (2014). the concept of sustainability in contemporary Islamic architecture and comparison of it with the concept of current sustainability. Journal of Islamic architecture, 2(5), 35.

Torjman, Sh. (2000). The Social Dimension of Sustainable Development, Caledon Institute Social Policy.

Yari, M., Hassan, M., Omidi, P., \& Sjadzadh, H. (2014). The role of interaction between human and environment in order to achieve sustainable urban development. the Second International Congress of constructions, architecture and urban development, Tabriz.

Zandieh, M., \& Parvardi nejad, S. (2010). sustainable development and its implications in the residential architecture of Iran. Journal of Housing and Rural Environment, 2-21.

\section{Copyrights}

Copyright for this article is retained by the author(s), with first publication rights granted to the journal.

This is an open-access article distributed under the terms and conditions of the Creative Commons Attribution license (http://creativecommons.org/licenses/by/4.0/). 